and stitched together; a loop of catgut was inserted at the lower end to prevent the accumulation of oozing. Then the skin was sutured, and a small gauze drain inserted at the top of the wound. The wound healed satisfactorily, the only incident being the appearance of a dampness on the bed sheet about the third day, which gradually extended down to the level of the loins. It was colourless, there were no constitutional symptoms, and, being aseptic, the dressing was not interfered with; only the sheet was changed. It never gave any trouble afterwards.

After-progress. - July 2rst. The temperature has remained normal since the operation. General condition good. Urine no longer ammoniacal Urotropin prescribed. Patient is able to flex each thigh slightly; she could not do so before the operation. The prick of a pin is felt on each leg as a tactile sensation, but is not painful. The touch of a finger is felt on the right leg but not on the left. July 23 rd. Knee-jerks present, no ankle clonus. Patient has still no control over the urine. July 26 th. Urine drawn off by catheter three times a day and bladder washed out with boric acid lotion. Urotropin given internally. She can feel the touch of a finger on the right leg but not on the left. The head of a pin is not felt on either leg. August 25th. Operation wound quite healed. She can flex at the hip and knee on each side, but cannot move the feet or toes September 3 rd. The catheter is still used; but the urine is occasionall passed spontaneously. She has now a slight sensation at the anus when facces are passed. September zoth. Considerable rigidity of the legs has developed, and there is a great tendency for them to be fexed at the hips and knees. October r5th. Patient can now dorsiflex feet and extend the toes. There is great rigidity of the leg to passive movements. January eoth, 190r. Catheter passed for the last time. January 25 th. Urine and faeces passed normally. Urine only contains a few pus cells. Legs very rigid. She can feebly flex and extend at all of the joints of the leg, but she is quite unable to stand. The knee-jerks are increased; ankle clonus is present on both sides; the plantar reflexes are present, and of the extensor type. The abdominal and epigastric reflexes are absent. The sensation, which has gradually improved since the operation, is now practically normal. The touch with the head of a pin, the prick of a pin, the sensations of hest and cold are felt in the normal manner all over both legs, and all over the abdomen and chest. The patient was discharged from the hospital on January 25th, rgor. She remained at home until the end of the year. when she was again admitted to the hospital. On January 7 th, r902, the patient is able to stand on the toes when supported with both hands on a table or chair back : but she is not able to walk alone. The movements of the right leg are feebler than those of the left. She cannot get the heels to the ground when standing supported. The right leg is very rigid; the left slightly rigid; both knee-jerks are increased ; there is ankle clonus on the right side, but not on the left. Sensation normal. The patient left the hospital in a few weeks, and remained at home until June, 1902. June 26th, rgo2. Patient can walk alone with the assistance of a walking stick in each hand. She can perform all the coarse movements of the legs, but the legs are still spastic, especially the right. The movements are much better than when she was in the hospital last. In July, 1902, a small cyst, about $\mathrm{I}$ in. in diameter, was found at the upper end of the operation scar where the gaaze drain had been inserted. The cyst contained clear fluid. To remove this cyst the skin was punctured at about an inch distance, and the cyst wall ruptured subcutaneously. The fluid removed was clear and water-like. The cyst was so opened to allow of,interstitial drainage afterwards, $;$ 'method considered by one of us (P.T.) to be safer than the excision usually recommended in meningocele. December and, 1902, the patient could walk alone with the aid of one stick. She was able to walk about the ward and to walk for a short distance in the street with the aid of one stick. She could perform all the coarse movements of the legs. There was, however, considerable rigidity of the legs, with increase of the reflexes. But sensation was normal. There was no affection of the bladder or rectum, and the patient felt quite well.

Owing to the spastic condition of the legs the recovery eannot be regarded as quite complete; but when we consider that before the operation there was total paralysis of both legs, paralysis of the bladder and rectum, and anaesthesia of the legs and lower part of the trunk, the results must be regarded as very satisfactory.

With reference to surgical treatment, the pathological anatomy of spinal hydatid cysts has revealed two points of great importance concerning their situation: (I) That the cysts causing the "compression myelitis" are usually extermal to the spinal dura mater (20 out of 24 cases, Colman ${ }^{1}$; (2) that in the majority of cases the cysts are on the posterior surface of the spinal dura mater (Maguire ${ }^{2}$ ). In the majority of cases, therefore, the cysts are situated on the surface of the dura (posterior) which is most easily exposed surgically; also the cysts, being usually extradural, can be removed without the dura mater being opened. - Further, according to Schmaus and Sacki and other pathologists, the cause of the paralysis at first is lacalised oedema of the cord; at a later pcriod degeneration of nerve elements and softening occur. Hence by early removal of the cysts there are good prospects of recovery from the " myelitic" symptoms. In 1o out of 25 cases analysed by Colman, the dorsal region of the cord was the seat of the "compression myelitis" caused by the cysts.

In many of the cases recorded the cysts have first developed in the subpleural or subperitoneal connective tissue, or in the muscles of the back (as in the case here recorded). After- wards they have extended through the intervertebral foramina into the vertebral canal, and then have spread in the longitudinal direction in the adipose tissue external to the spinal dura mater.

In most of the cases recorded symptoms of compression of spinal nerve roots-radiating pains-have occurred first, and later paraplegia, anaesthesia, and bladder, and rectal sym. ptoms have developed. The onset of the paraplegia has usually been gradual.

As regards diagnosis, the symptoms just mentioned may be attribated to spinal hydatid cysts when examination reveals the presence of hydatid cysts in some other part of the body, and no other cause of "compression myelitis" can be detected. In some cases (as in that here recorded) a small cyst has been felt in the back close to the vertebral spines, and when this has been punctured the fluid has had the characters of hydatid fluid, and has contained scolices or hooklets.

The only treatment of service is removal of the hydatid cysts. But usually when the operation has been performed the compression has been of long standing, the cord has never recovered its functions, and the case has terminated fatally. By early recognition and operation many cases could be saved.

We have found references to four successful operations for spinal hydatid in medical literature, and probably a few others are on record. Putnam and Warren quote a case recorded by Lloyd, ${ }^{3}$ and another reported by Szckeres. ${ }^{4}$ In both the cysts were extradural. The results of operation are stated to be " recovery," but, we have not been able to obtain the original articles. Hahn ${ }^{5}$ has recently mentioned a case in which recovery followed his operative treatment. Sir William Gowers ${ }^{6}$ mentions a case in which Sir Victor Horsley removed a number of hydatid cysts compressing the cord, "but the damage was too great to allow the recovery of the extensive atrophic paralysis produced in the right thigh and hip muscles."

1 Colman, W. S., St. Thomas's Hospital Reports, vol. Xxviii, p. $3^{62}$ 2 Maguire, R., Brain, vol. $x, p .45 x, 1888$. 3 and 4 Lloyd and Szckeres quoted by Putnam and Warren, American Journ. of the Med. Sciences, Report.) 6 Gowers 8 ir Wm and Taj. Chirurgie, No. 14, p. 398, 1902 (Soc1ety 3rd edition, London, vol. i, p. 306. 7 Ransom and Anderson, BRITIs, MEDICAL JOURNAL, vol. ii, 1891 , p. 1144

\section{CASE OF hYDATID OF THE PLEURA.} BY

W. B. RANSOM, M.A., M.D., and W. M. WILLIS, F.R.C.S F.R.C.P.,

Physician to the General Hospital, ENG., Nottingham

Assistant Surgeon to the General Hospital, Nottingham.

Medical Notes by DR. W. B. RANsom.

History.-Miss T., aged 43 , consulted me first in September, 1901. She had been out of health for two years, her illness having begun with symptoms that suggested gastric ulcer to her doctor. Thus, she had had severe and sudden attacks of pain in the epigastric region, sometimes independently of food and not associated with vomiting or jaundice. She had been kept on milk diet for three months, and ultimately the gastric symptoms subsided. In January, 1901, however, she felt new pains in the chest between the left breast and clavicle. In March she consulted two eminent medical men in the North of England, who appear to have suspected a new growth of the lung There had been some cough during the whole of the year, and a considerable quantity of phlegm since June, but no haemoptysis. She had lost a good deal of flesh in the earlier part of the sear, but had gained $6 \mathrm{lb}$. between April and September.

State on Examination.-The chest was found to be normal except for an area of absolute dullness at the left apex in front, extending from the clavicle to the third intercostal space, and inclining slightly downwards towards the axilla. The area was continuous with the cardiac dullness, and in it breath and voice sounds were extremely faint, but no rales or crepitations. were heard. There was no enlargement of glands, no abnormal pulsation, and the heart, larynx, and abdomen appeared normal. In the sputum, which was abundant and muco-purulent, neither tubercle bacilli, actinomyces, nor fragments of new growth or hydatid were discevered. The patient was ordered potassium iodide, and sent away to the country.

Progress. - In a month all expectaration stopped, she gained 
$4 \mathrm{lb}$. in weight, and was able to walk ten miles a day, while her temperature remained normal. The physical signs, however, were unaltered, except that the breath sounds were now quite absent in the dull area. By Christmas she had gained $8 \mathrm{lb}$., in spite of a febrile attack of "bronchial catarrn" in November-for which she was attended by Dr. Fraser, of Carlton-and felt very well, but was again spitting large quantities of phlegm. Suspecting hydatids, I repeatedly sought for fragments of membrane in the sputum, but in vain. During the whole of February she was in bed, under Dr. Fraser's care, with signs of general catarrh of the left lung, fever, and incessant cough. When I gaw her again in April she was, therefore, not so well, had lost flesh, and complained of pains in the front of the left half of the chest and in the axilla, while she coughed a good deal of frothy, watery fluid. There was now heard pleuritic friction in the axilla outside the dull area, which had slightly extended. Although there was no history of syphilis, she had been taking potassium iodide in large doses for nearly four months.

Didgnosis.-Feeling that hydatid cyst in the pleural cavity in front of the lelt lung was a probable diagnosis, I now urged her not longer to postpone surgical treatment, which Mr. Morley Willis after consultation agreed to carry out, deliberate operation being considered preferable to a preliminary exploration by a trocar.

As will be seen by Mr. Willis's account the operation confirmed the diagnosis. It is probable that the epigastric pains, which occurred a year before the thoracic troubles and at first appeared to have no connexion with the latter, may have been due to hydatids in the neighbourhood of the stomach and liver.

It should be added that the patient before consenting to the operation consulted Dr. Lauriston Shaw, who agreed,with the diagnosis and proposed treatment.

[January 3 Ist, 1903.- Since these notes were sent to the British Medicas Journal, I have had in hospital a man in whom the symptoms and signs were identical with those above-mentioned, with two exceptions. On the one hand there has been no expectoration, on the other there is paralysis of the left vocal cord. This week Mr. Hogarth explored the second left intercostal space and revealed a solid mass of growth, probably sarcoma. The patient has had no visibly enlarged glands, no fever and but slight wasting. The involvement of the recurrent laryngeal nerve was the one positive sign pointing to new growth.]

Surgical Notes by Mr. W. M. WILLIs.

The foregoing are Dr. Ransom's notes of this interesting case. My connexion with it began on May 6th, 1902, when saw the patient with Dr. Ransom with a view to operation.

Having heard the history, I carefuily examined her chest and found the conditions described still present, namely, an area of absolute dullness at the left apex in front, extending into the axilla, and continuous below with the heart duliness. Over this area were to be heard breath sounds and vocal resonance only very faintly, and there were no râles or other adventitious sounds.

I failed to satisfy myself completely on this examination, which was the first I had made of the patient, whether the area of dullness was due to a condition of the lung itself, or to a condition of the pleura and not in communication with the lung, or of an affection of the pleura plus a communication with the bronchus. However, I expressed my willingness at the patient's request, and on the suggestion of Dr. Ransom, to explore this dull area.

She was admitted to a private nursing home in this town, and a day or two before operating I took the opportunity of again very carefully examining her chest. The conditions were unaltered, but I observed that there were distinct signs that the heart was slightly displaced downwards and to the right, so that the apex beat was felt in a space lower than is usual and somewhat internal to the normal position. I therefore felt justified in concluding that there was a condition of the pleura, with or without a small communication with the bronchus, and that exploration was entirely justifiable. With regard to an exact diagnosis, I did not feel that it would be possible to affirm much. That we could exclude a condition of the lung itself was an opinion that the examination warranted, but what condition of the pleura existed was by no means certain. The length of the history of the condition was opposed to new growth, at least of a malignant variety, and the exceeding uncommonness of a localized pleurisy or empyema in this situation rendered such a diagnosis improbable.

The fact of the patient having been resident in Australia was worth bearing in mind, and, having excluded other eonditions, this somewhat favoured the idea of hydatid cyst. I was therefore, before operating, in this position-that the patient had a condition of the left apical pleura which was probably not inflammatory, probably not new growth, and that there was reason for supposing, at least, that it might be a hydatid cyst. This will appear sufficiently vague, but I felt that it was enough to justify an exploratory operation.

Operation.-Accordingly, on May I 7 th I proceeded to investigate the condition. Chloroform was administered, and the arm was extended at a right angle with the chest. An incision was then made some 4 in. in length, the centre of which corresponded with the second intercostal space in the midclavicular line. The fibres of the pectorals were separated and held aside with retractors, and the intercostals of the second space were then defined. The intercostals were incised and the parietal pleura exposed. The needle of an exploring syringe was then thrust into the dull area at the point indicated, and, the piston of the syringe being with-drawn, perfectly clear fluid filled the syringe. The opening: in the intercostal space was now enlarged, and the finger was inserted into the cavity, from which a large quantity of fluid was issuing. The downward limit of the cavity could be reached, and the pericardium felt with the heart pulsating. within it, but the upward limit could not be reached, it appearing to occupy the whole apex of the thorax on this side. The whole cavity was smooth-lined, and was a hydatid cyst of the pleura, with apparently no communication with the lung; but the lung was displaced by the pressure of the cyst, which contained upwards of a pint of fluid. A largesize drainage tube was inserted, and the skin incision closed except where the tube issued.

After-progress. - The wound was dressed daily, and in the course of ten days or a fortnight the whole of the cyst wall was expelled through the opening aided by traction as it presented. The bulk of it was expelled on one day entire, and was as large as the human urinary bladder. Vomiting was extremely troublesome for two or three days, so much so that for twentyfour hours she was fed per rectum. The lung has gradually expanded. and the present condition of the patient is as follows: There is no cough, she can walk ten or twelve miles with ease, eats and sleeps well, has put on flesh. There still remains, however, a sinus in the chest wall, leading into cavity which appears to be as large as a good size orange; so that, though there has been some recovery of the lung and it has expanded considerably, it has by no means completely done so. From the sinus there issues a thin sero-purulent fluid in small quantity, but necessitating daily dressing by the patient. It is probable that the cavity will only be obliterated by allowing the chest to fall in, and to this end it will be necessary to perform another operation, and remove portions of several ribs probably of the second, third, and fourth.

[February, 1903.- Since the abuve was written I have removed some $2 \frac{1}{2} \mathrm{in}$. of both the second and third ribs in front, and as the parts removed constituted the entire bony boundary of the remaining cavity there is every reason to believe that in time it will become quite obliterated by the falling in of its front wall. This was done on January $15^{\text {th }}$ and the patient is progressing well.]

\section{THE EFFECTS OF VACCINATING DURING A MENSTRUAL PERIOD.}

BX E. RUMLEY DAWSON, L.R.C.P.LOND., M.R.C.S., Leyton.

The following case, in which haematemesis was associated with menstruation, appears to be of interest :

R. R aged 29 , single, hotel chambermaid, had been primarily vaceinated as an infant. She was a robust, healthy, and not anaemic woman, who had always been very regular in her menstruation. Each menstral period had always been very regular in her menstich the discharge was profuse, and of a lasted six full days, during which the discharge was profuse, days with great regularity. She periods recurred every twaps two or three times during a year, from slight indigestion, which was not sufficiently clently sover dyspeptic, and did not have pain after her food; she was not a bilious.
subject, and was not liable to vomiting. She was of very abstemious subject,

She was, and had been for some time past, very well indeed, wh $n$ about 